\title{
Effect of Grape Juice Consumption and Red Wine in the Osteoprotegerin Level and Systolic Blood Pressure in Rats Wistar Fed High - Fat Diet
}

\author{
Teresa Palmisciano Bedê, Vânia Mattoso, Ana Cláudia Pascoal, Eduardo de Salvo Castro, \\ Carlos Alberto Soares da Costa, Gilson Teles Boaventura, Vilma Blondet de Azeredo
}

Department of Nutrition and Dietetics, Federal Fluminense University, Niteroi, Brazil

\section{Email address:}

teresabd@gmail.com (T. P. Bedê), vaniamattoso@yahoo.com.br (V. Mattoso), aclaudinhauff@gmail.com (A. C. Pascoal), edu.s.c_1234@hotmail.com (E.de S. Castro), nutcarlos@hotmail.com (C. A. S. da Costa), gilsontb@gmail.com (G. T. Boaventura), vilma.blondet@gmail.com (V. B. de Azeredo)

\section{To cite this article:}

Teresa Palmisciano Bedê, Vânia Mattoso, Ana Cláudia Pascoal, Eduardo de Salvo Castro, Carlos Alberto Soares Costa, Gilson Teles Boaventura, Vilma Blondet de Azeredo. Effect of Grape Juice Consumption and Red Wine in the Osteoprotegerin Level and Systolic Blood Pressure in Rats Wistar Fed High - Fat Diet. International Journal of Nutrition and Food Sciences. Vol. 5, No. 3, 2016, pp. 170-174. doi: $10.11648 /$ j.ijnfs. 20160503.13

Received: March 21, 2016; Accepted: March 31, 2016; Published: April 16, 2016

\begin{abstract}
High-fat diet contributes to reduction of bone mineral density and development of cardiovascular diseases. Highfat diet promotes the release substrate for formation of atheromatous plaques as well as increase production of cytokines and prostaglandins, interfering negatively in the concentration of osteoprotegerin - responsible for inhibiting the osteoclastogenesis. The interest by functional foods and their effects on diseases prevention is growing. This study evaluated the effect of whole grape juice consumption and red wine in the osteoprotegerin level and blood pressure in rats fed fat diet. They were used 40 rats Wistar Albino, adult, divided in groups: control - balanced diet; hiperlipydic - high-fat diet; wine - red wine + high-fat diet; juice - grape juice + high-fat diet. Water and ration were offered ad libitum and grape juice and red wine daily, during 60 days. Blood pressure was measured by a tail plestimograph and interleukin 6 (IL-6) and osteoprotegerin by ELISA. Results are expressed as mean and standard deviation. For comparison it was used ANOVA and Tukey as post-test, considering $\mathrm{p}<0.05$. Systolic blood pressure $(\mathrm{mmHg}$ ) was lower in grape juice group than hiperlipydic and red wine groups and similar to control group. IL-6 level (pg/mL) was lower in grape juice group than wine group, but it was similar to control and hiperlipydic groups. Hiperlipydic and wine groups showed lower osteoprotegerin level $(\mathrm{pg} / \mathrm{mL})$ than control and juice groups. Daily consumption of grape juice seems minimize the effects of high-fat diet in cardiovascular diseases risk and bone demineralization, by maintaining adequate concentration of osteoprotegerin and the systolic blood pressure in animals.
\end{abstract}

Keywords: Polyphenols, Grape Juice, Red Wine, High - Fat Diet, Blood Pressure, Interleucin 6, Osteoprotegerin, Wistar Rats

\section{Introduction}

The diet quality has important implications for the human health. High-fat diet increases the risk of overweight / obesity and is associated with risk factors for chronic noncommunicable diseases (NCDs) such as cardiovascular disease (CVD) and bone disease [1].

The high-fat content in the diet triggers inflammatory processes, increases the production of prostaglandins and interleukins such as interleukin 6 (IL-6) and prostaglandin E2
(PGE2). Moreover, this type of diet induces the oxidative stress with increased production of reactive oxygen species (ROS), and increases the serum lipids level $[2,3,4,5]$. These physiological changes may promote increased blood pressure since that inflammatory cytokines and ROS can affect the renin-angiotensin system, and the high level of serum lipids can be oxidized and used as substrates for the formation of atherosclerotic plaques, directly interfering in the structure and functionality of the blood vessels [2, 3, 6, 7].

High-fat diets, particularly in saturated fat, also reduce 
bone mineral density. It can lead to the alteration of morphogenesis and affect the remodeling of bone due to the inflammatory factors, directly related to the osteoprotegerin level (OPG) [2, 3, 4, 5]. Bone homeostasis is a process controlled by the balance of activity between osteoblasts and osteoclasts. Osteoblasts are the cells responsible for the production and mineralization of bone matrix [8,9], while osteoclasts promote bone resorption. OPG is produced by osteoblasts a protein that acts inhibiting the maturation and activation of osteoclasts and prevents bone resorption. However, the secretion of OPG is decreased by inflammatory markers. The level of IL-6 and PGE2 is increased by the consumption of a high-fat diet and it is stimulate the preosteoclast recruitment and the higher bone resorption [10].

Nowaday, with the high mortality rate from NCDs has been an increase in the number of studies on the functional properties of food and about bioactive compounds that may promote health and prevent diseases. Among these compounds are the polyphenols, which have many benefits described in the literature as a potent antioxidant and antiinflammatory action. Polyphenols are found in grapes and their by-products such as grape juice and red wine [11, 12].

In recent years, the association between osteoporosis and cardiovascular disease has been described and shows the epidemiological and physiopathological similarities. It highlights the relationship of dietary habits in the development and prevention of these diseases, such as excessive consumption of saturated fat acid and the intake of bioactive compounds, respectively [13]. Therefore, it is relevant to study the consumption of food with functional properties as a protective factor against diseases caused or aggravated by high-fat diet. In view of this, this study aims to evaluate the effect in whole red grape juice consumption and red wine on the systolic blood pressure, IL-6 and OPG serum level, of rats fed high-fat diet.

\section{Materials and Methods}

\subsection{Study Design}

The research protocol was approved by the Ethics Committee on Animal Use at the Fluminense Federal University (UFF), Niteroi, Brazil, under hearing number 00216/10. All procedures were in accordance with Brazilian School of Animal Experimentation - National Council for Animal Experiments Control (CONCEA).

The experiment was performed at the Laboratory of Experimental Nutrition (LabNE), Emilia de Jesus Ferreiro Nutrition School, UFF. Forty female Wistar rats, with ninety days, were obtained from the colony kept by the LabNE and were divided into four groups: control group (CG) was fed a balanced diet casein-based; Hiperlipydic group (HG) was fed high-fat diet; Whole red grape juice group (JG) was fed highfat diet and whole red grape juice $(15 \mathrm{~mL} /$ day); Red wine group (WG) - was fed high-fat diet and red wine $(10 \mathrm{~mL} /$ day).

All animals were kept in an individual's cages with controlled temperature $\left(21-23^{\circ} \mathrm{C}\right)$ and light-dark cycle $(12 / 12$ h). Water and diets were offered ad libitum and red wine and whole red grape juice were offered daily.

Body mass and feed intake of all animals were recorded weekly using precision scales (BioPrecisa ${ }^{\circledR}$ JY 50001, precision $0.01 \mathrm{~g}$ ) and beverage consumption (water, whole red grape juice and red wine) were recorded daily for graduate beaker.

\subsection{Diets and Beverages}

Red wine (Cabernet Sauvignon) and whole red grape juice were obtained from local trade. Diets (balanced and high-fat) were prepared at the place of experimentation by members of the research and the chemical composition of the diets used is described in Table 1. The balanced diet was prepared according to the recommendations of the American Institute of Nutrition - 93M - for the maintenance of the nutritional needs of adult animals. The balanced diet contained $4 \%$ of lipid (soy oil) and the high-fat diet contained $20 \%$ of saturated fat (lard).

Table 1. Chemical composition of the balanced diet and high-fat diet used in the experiment.

\begin{tabular}{llllll}
\hline & \multicolumn{2}{l}{ Balanced diet } & \multicolumn{2}{l}{ High-fat diet } \\
\hline & $\begin{array}{l}\text { \%/100g } \\
\text { ration }\end{array}$ & $\begin{array}{l}\text { kcal/100g } \\
\text { ration }\end{array}$ & $\begin{array}{l}\text { \%/100g } \\
\text { ration }\end{array}$ & $\begin{array}{l}\text { kcal/100g } \\
\text { ration }\end{array}$ \\
\hline Carbohydrate & 77,1 & 308,4 & 61,07 & 224,28 \\
Protein & 12,95 & 51,8 & 12,95 & 51,8 \\
Lipid & 4 & 36 & 20 & 180 \\
Total & 94,05 & 396,2 & 94,02 & 456,08 \\
\hline
\end{tabular}

(kcal) kilocalories

\subsection{Measurement of Blood Pressure}

Arterial blood pressure was measured by tail plethysmography (Insight $\left.{ }^{\circledR}\right)$ as previously described by $\mathrm{Ni}$ et al., 1998 [14]. Rats were preheated in a chamber at $40^{\circ} \mathrm{C}$ for 10 minutes, then placed in plastic restrainers. A cuff with a pneumatic pulse sensor was attached to the tail. Rats were allowed to habituate to this procedure for 7 days before experiments were performed. Blood pressure values were recorded, at least in three consecutives readings, obtained from each rat. The procedure was performed in a climatecontrolled room.

\subsection{Sacrifice and Biochemical Tests}

At the end of the experiment, the animals were submitted to vaginal wash procedure for determining the estrus cycle phase. Rats in the "estrus" phase were separated for sacrifice after six hours of fasting.

The animals were anesthetized with an intraperitoneal injection of xylazine hydrochloride: ketamine (1: 1) at a dose of $0.1 \mathrm{~mL} / 200 \mathrm{~g}$ body weight. Blood samples were collected via cardiac puncture, aliquoted, centrifuged at $3000 \mathrm{rpm}$, during 20 minutes, for obtaining plasma and serum. Serum samples were used to determine the OPG and IL-6 concentration, by Enzyme-Linked Immunosorbent Assay (ELISA). 


\subsection{Statistical Analysis}

The results were presented using descriptive statistics such as mean and standard deviation. One-way ANOVA was used to compare means among groups and Tukey test was used as post-test. Significance level of $5 \%$ was adopted using the GraphPad InStat software (version 3.10, 2009) to perform the analyses.

\section{Results}

At the end of the experiment, it was observed that water intake was similar in all groups, the ingestion of beverages rich in polyphenols was higher $(\mathrm{p}<0.05)$ in JG than $\mathrm{WG}$ and in the groups that received the high-fat diet was observed a trend of lower feed intake than in CG. However, there was no difference in the total energy consumed daily by the animals, neither with regards to the increase of body weight, throughout the study "Table 2".

Table 2. Beverage consumption, feed intake, total energy consumed and body weight gain of the different study groups.

\begin{tabular}{lllll}
\hline & $\begin{array}{l}\text { Beverage } \\
\text { consumption } \\
\text { rich of } \\
\text { polyphenols } \\
\text { (mL/100gBM) }\end{array}$ & $\begin{array}{l}\text { Feed intake } \\
(\mathbf{g} / \mathbf{1 0 0 g B M})\end{array}$ & $\begin{array}{l}\text { Total energy } \\
\text { consumed } \\
\text { (kcal/100gBM) }\end{array}$ & $\begin{array}{l}\text { Body } \\
\text { weight } \\
\text { variation } \\
(\mathbf{g})\end{array}$ \\
\hline CG & - & $6.01 \pm 1.34$ & 22.59 & $77.93 \pm 47.75$ \\
HG & - & $5.15 \pm 1.16$ & 23.48 & $86.37 \pm 51.79$ \\
JG & $3.74 \pm 1.66^{\mathrm{b}}$ & $4.84 \pm 1.29$ & 24.31 & $76.79 \pm 54.15$ \\
$\mathrm{WG}$ & $1.95 \pm 0.32^{\mathrm{a}}$ & $4.67 \pm 1.61$ & 22.96 & $80.02 \pm 61.28$ \\
\hline
\end{tabular}

Different superscript letters represent significant differences between the groups ( $\mathrm{p}<0.05)$; Control group (CG) - the balanced feed; Hyperlipidic group (HG) - high-fat diet; Whole red grape juice group (JG) - high-fat diet + whole red grape juice, Red wine group (WG) - high-fat diet + red wine. Total energy consumed - equivalent to kilocalories offered by diet added to drinks. $\mathrm{mL}$ - milliliter; $\mathrm{g}$ - grams; BM - body mass; kcal - kilocalories; $\mathrm{p}$ value* within same column. Statistical analysis: one-way ANOVA and Tukey for mean comparison between groups.

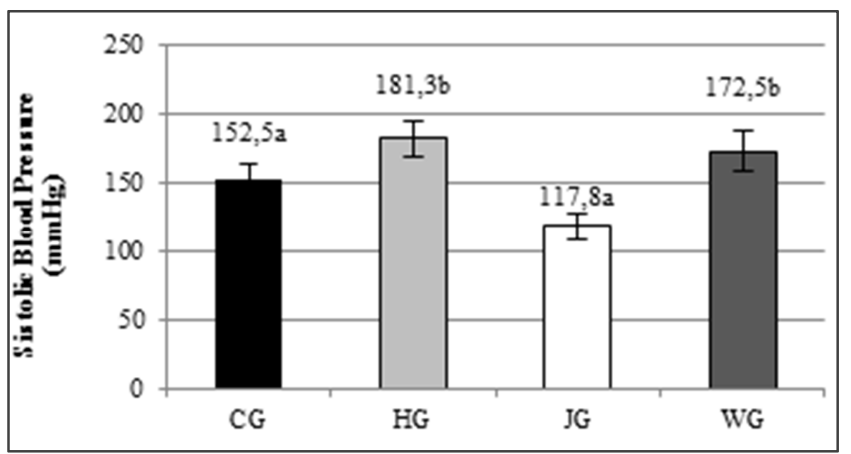

Figure 1. Systolic blood pressure ( $\mathrm{mmHg}$ ) of different study groups.

Different superscript letters represent significant differences between the groups ( $\mathrm{p}<0.05$ ); Control group $(\mathrm{CG})$ - the balanced feed; Hyperlipidic group (HG) - high-fat diet; Whole red grape juice group (JG) - high-fat diet + whole red grape juice, Red wine group (WG) - high-fat diet + red wine. Statistical analysis: one-way ANOVA and Tukey for mean comparison between groups.
The blood pressure of animals of the JG (117.80 \pm $0.24 \mathrm{mmHg}$ ) showed lower $(\mathrm{p}<0.05)$ systolic blood pressure compared to $\mathrm{HG}(181.37 \pm 12.86 \mathrm{mmHg})$ and $\mathrm{WG}(172.55 \pm$ $15.24 \mathrm{mmHg})$, but similar to the CG $(152.53 \pm 10.30 \mathrm{mmHg})$ - Figure 1.

Concentration of IL-6 $(\mathrm{pg} / \mathrm{mL})$ was lower $(\mathrm{p}<0.05)$ in JG $(39.37 \pm 5.25 \mathrm{pg} / \mathrm{mL})$ than in the WG $(51.49 \pm 7.17 \mathrm{pg} / \mathrm{mL})$, but it was similar to $\mathrm{CG}(42.73 \pm 6.85 \mathrm{pg} / \mathrm{mL})$ and $\mathrm{HG}$ $(43.42 \pm 7.10 \mathrm{pg} / \mathrm{mL})$ - Figure 2.

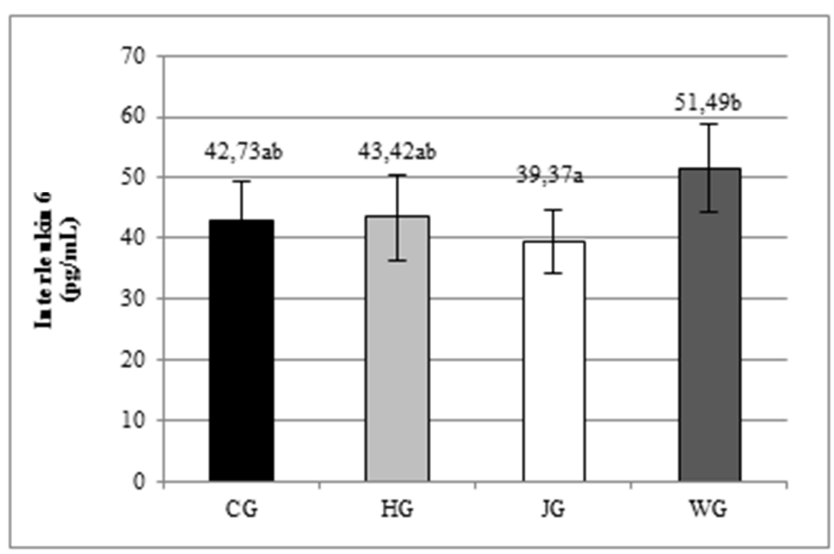

Figure 2. Seric interleukin 6 level $(\mathrm{pg} / \mathrm{mL})$ of the differents studied groups

Different superscript letters represent significant differences between the groups $(\mathrm{p}<0.05)$; Control group $(\mathrm{CG})$ - the balanced feed; Hyperlipidic group (HG) - high-fat diet; Whole red grape juice group (JG) - high-fat diet + whole red grape juice, Red wine group (WG) - high-fat diet + red wine. Statistical analysis: one-way ANOVA and Tukey for mean comparison between groups.

Regarding OPG $(\mathrm{pg} / \mathrm{mL})$, the HG $(198.0 \pm 40.47 \mathrm{pg} / \mathrm{mL})$ and WG $(264.4 \pm 34.39 \mathrm{pg} / \mathrm{mL})$ showed lower OPG level $(\mathrm{p}<0.05 \mathrm{pg} / \mathrm{mL})$ than $\mathrm{CG}(481.66 \pm 240.67 \mathrm{pg} / \mathrm{mL})$ and $\mathrm{JG}$ $(407.33 \pm 132.08 \mathrm{pg} / \mathrm{mL})$ - Figure 3.

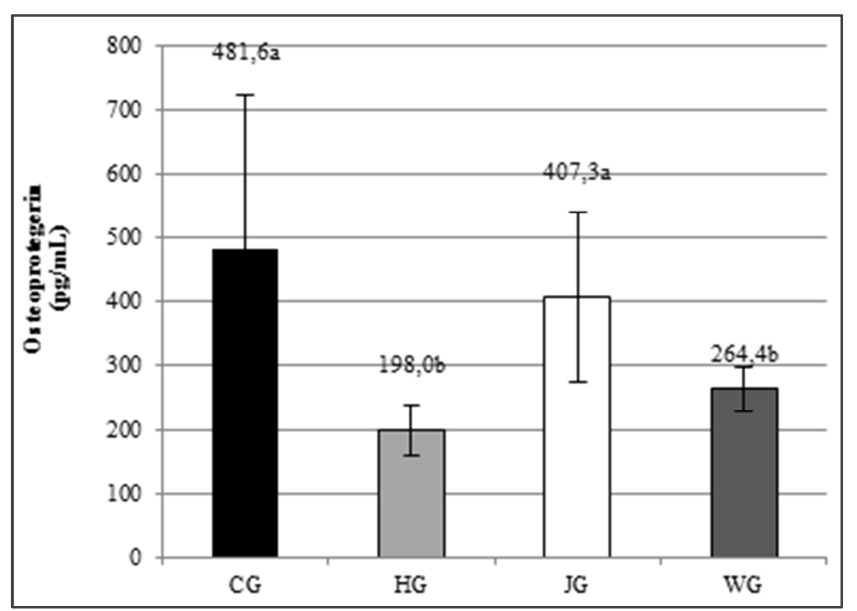

Figure 3. Seric osteoprotegerin level $(\mathrm{pg} / \mathrm{mL})$ of the different groups studied.

Different superscript letters represent significant differences between the groups $(\mathrm{p}<0.05)$; Control group $(\mathrm{CG})$ - the balanced feed; Hyperlipidic group (HG) - high-fat diet; Whole red grape juice group (JG) - high-fat diet + whole red grape juice, Red wine group (WG) - high-fat diet + red wine. Statistical analysis: one-way ANOVA and Tukey for mean comparison between groups. 


\section{Discussion}

Several studies have linked the consumption of high-fat diet with risk factors for cardiovascular and bone disease [2, $3,4,5]$. The excess of dietary fat has been associated with atherogenic processes and osteoporosis triggered by different factors that can be caused by changes in serum lipid levels and inflammatory markers $[5,10]$.

In addition, high-fat diets are also related to the body weight gain $[15,16]$. However, throughout the experiment there was no difference in food consumption and body mass gain of the animals, but there was a trend of lower feed intake in the groups that received the high-fat diet. It is suggested that the animals are able to regulate their feed intake by the total consumed energy $[16,17,18]$. The same was observed in the study by [19], they observed lower dietary intake in the group that received diet rich in fat compared to the group that consumed balanced diet. In the present study, we observed lower feed intake of animals from JG and WG. These results are probably related to the intake of grape juice and red wine, respectively. It can be explained due to the fact that these beverages are additional source of energy and may have contributed to the satiety of animals.

There are reports that the bioactive compounds in the grape juice are cardioprotective, primarily for its antioxidant and anti-inflammatory activity [20, 21, 22, 23]. A study [24] showed that rats fed with high-fat diet for 12 weeks leaded to a significant increase in systolic blood pressure. Similar results were found in this study, where the consumption of grape juice seems to minimize the effect of the high- fat diet on systolic blood pressure in animals that received grape juice daily. Studies indicate that the greatest benefit of the grape juice is its ability to act on the endothelium, increasing nitric oxide synthesis and preserving the endothelium-dependent vasodilation, due to the antioxidant capacity of the drink [22]. Moreover, other authors assert that polyphenols of grape juice can minimize the increase in the low density lipoprotein level (LDL) and prevent oxidation, while reduces the formation of atherosclerotic plaques in blood vessels, preventing platelet aggregation and oxidative damage $[25,26]$. These hypotheses help explain the results found in the JG.

Animals fed during weeks with high-fat diet showed inflammatory changes such as increased levels of PGE2, ROS [2] and increase in serum pro-inflammatory cytokines (IL-1 - interleukin 1, TNF - tumor necrosis factor, IL-6) [3]. However studies have shown that polyphenols present in the grape juice and red wine are protective to the organism, inhibiting pro-inflammatory pathways, and reducing the expression and synthesis of TNF, IL-1 and IL-6 released from monocytes [27]. Corroborating these finds, [28] found lower values of IL-6 in the group receiving high fat diet supplemented with resveratrol, compared to the control group. The findings of the present study are in accordance with the literature [28], where was observed a trend of lower IL-6 level, probably due to anti-inflammatory effect of the polyphenols present of the grape juice. It can be emphasized that these effect was not observed in animals that received red wine, suggesting that the alcohol content of the wine can inhibit the anti-inflammatory effect of the polyphenols.

In relation to OPG, it is suggested that the high level of IL-6 in the HG and WG may have acted suppressing the expression and release of OPG. The OPG acts on bone physiology and it is responsible for inhibiting osteoclast activity in bone resorption. The lower level of OPG enables greater bone resorption, with increased serum concentrations of calcium and risk of vascular calcification in the arteries, promoting and / or exacerbating the atherosclerosis process which can be triggered by high-fat diets. As a result of physiological changes, blood vessels lose elasticity, an increase cardiac work, increased blood pressure and increased mortality from cardiovascular and bone disease $[4,5]$.

\section{Conclusion}

The consumption of whole red grape juice seems to be able to minimize the effects of the high fat diet on the cardiovascular risk and in the bone desmineralization, maintaining proper systolic blood pressure and the adequate level of IL-6 and osteoprotegerin in the animals. It can be emphasize that the results of this study suggest that the consumption of red wine did not show any benefit to the animals.

\section{Acknowledgements}

We thank the funding institutions Foundation for Research of the State of Rio de Janeiro (FAPERJ) and National Counsel of Technological and Scientific Development (CNPq).

\section{References}

[1] Levy, R. B., Claro, R. M., Mondini, L., Sichieri, R. and Monteiro, C. A. Distribuição regional e socioeconômica da disponibilidade domiciliar de alimentos no Brasil em 20082009. Rev. Saúde Pública. Vol. 46, No 1, 2012, pp. 6-15.

[2] Zhang, X., Dong, F., Ren, J., Driscoll, M. J. and Culver, B. High dietary fat induces NADPH oxidase-associated oxidative stress and inflammation in rat cerebral cortex. Experimental neurology. Vol. 191, № 2, 2005, pp. 318-325.

[3] De Souza, C. T., Araujo, E. P., Bordin, S., Ashimine, R., Zollner, R. L., Boschero, A. C., and Velloso, L. A. Consumption of a fat-rich diet activates a proinflammatory response and induces insulin resistance in the hypothalamus. Endocrinology. Vol. 146, № 10, 2005, pp.4192-4199.

[4] Morony, S., Tintut, Y., Zhang, Z., Cattley, R. C., Van, G., Dwyer, D.... and Demer, L. L. Osteoprotegerin inhibits vascular calcification without affecting atherosclerosis in ldlr (-/-) mice. Circulation. Vol. 117, No 3, 2008, pp. 411-420.

[5] Parhami, F., Tintut, Y., Beamer, W. G., Gharavi, N., Goodman, W., and Demer, L. L. Atherogenic High-Fat Diet Reduces Bone Mineralization in Mice. Journal of Bone and Mineral Research. Vol. 16, N 1, 2001, pp. 182-188. 
[6] Santana, A. B. C., Souza Oliveira, T. C. D., Bianconi, B. L., Barauna, V. G., Santos, E. W. C. O., Alves, T. P., .. and Krieger, J. E. Effect of high-fat diet upon inflammatory markers and aortic stiffening in mice. BioMed research international. Vol. 2014, 2014.

[7] Fyhrquist, F., and Saijonmaa, O. Renin-angiotensin system revisited. Journal of internal medicine. Vol. 264, No 3, 2008, pp. 224-236.

[8] Mackie, E. J. Osteoblasts: novel roles in orchestration of skeletal architecture. The international journal of biochemistry \& cell biology. Vol. 35, No 9, 2003, pp. 1301-1305.

[9] Cerri, P. S. Osteoblasts engulf apoptotic bodies during alveolar bone formation in the rat maxilla. The Anatomical Record Part A: Discoveries in Molecular, Cellular, and Evolutionary Biology. Vol. 286, № 1, 2005, pp. 833-840.

[10] Yasuda, H., Shima, N., Nakagawa, N., Yamaguchi, K., Kinosaki, M., Mochizuki, S. I.... and Suda, T. Osteoclast differentiation factor is a ligand for osteoprotegerin/osteoclastogenesis-inhibitory factor and is identical to TRANCE/RANK. Proceedings of the National Academy of Sciences. Vol. 95, No 7, 1998, pp. 3597-3602.

[11] Vogel, P., Machado, I. K., Garavaglia, J., Zani, V. T., de Souza, D., and Morelo, S. D. B. Polyphenols benefits of olive leaf (Olea europaea L) to human health. Nutrición hospitalaria: Organo oficial de la Sociedad española de nutrición parenteral y enteral. Vol. 31, No 3, 2015, pp. 1427-1433.

[12] Lucile Tiemi, A. B. E., da Mota, R. V., Lajolo, F. M., and Genovese, M. I. Compostos fenólicos e capacidade antioxidante de cultivares de uvas Vitis labrusca L. e Vitis vinifera L. Ciênc. Tecnol. Aliment. Vol. 27, N 2, 2007, pp. 394-400.

[13] Qi, L., Shen, H., and Ordovas, J. M. Hearts and bones. Nutrition, Metabolism and Cardiovascular Diseases. Vol. 13, $\mathrm{N}^{\mathrm{o}} 3,2003$, pp. $165-174$.

[14] Ni, Z., Wang, X. Q., and Vaziri, N. D. Nitric oxide metabolism in erythropoietin-induced hypertension effect of calcium channel blockade. Hypertension. Vol. 32, № 4, 1998, pp. 724729 .

[15] Duarte, A. C. G. D. O., Fonseca, D. F., Manzoni, M. S. J., Soave, C. F., Sene-Fiorese, M., Dâmaso, A. R., and Cheik, N. C. Dieta hiperlipídica e capacidade secretória de insulina em ratos. Rev. Nutr. Vol. 19, No 3, 2006, pp. 341-348.

[16] Borba A. J., Rocha, M. G. M, Da Silva, M. F, Tibúrcio, D. T. S, Pereira, A. A. L., Dos Reis, L. C. and Thedei Júnior, G. Dieta hiperlipídico-proteica e obesidade. Rev. Nutr. Vol. 24 No 4, 2011, pp. 519-528.

[17] Mahan L. K. and Escott-Stump S. KRAUSE: alimentos, nutrição e dietoterapia. $10^{\mathrm{a}}$ ed. São Paulo: Roca, p.13, 2002.
[18] Westerpep-Platenga M. S. Effects of energy density of daily food intake on long-term energy intake. Physiology \& Behavior. Vol. 81, No 5, 2004, pp. 765-771.

[19] Moura, L. P. D., Dalia, R. A., Araújo, M. B. D., Sponton, A. C. D. S., Pauli, J. R., Moura, R. F. D., and Mello, M. A. R. D. Alterações bioquímicas e hepáticas em ratos submetidos à uma dieta hiperlipídica/hiperenergética. Revista de Nutrição, 2012, pp. 685-693.

[20] Yadav, M., Jain, S., Bhardwaj, A., Nagpal, R., Puniya, M., Tomar, R.... and Yadav, H. Biological and medicinal properties of grapes and their bioactive constituents: an update. Journal of Medicinal Food. Vol. 12, No 3, 2009, pp. 473-484.

[21] Dani, C., Oliboni, L. S., Pasquali, M. A., Oliveira, M. R., Umezu, F. M., Salvador, M.... and Henriques, J. A. Intake of purple grape juice as a hepatoprotective agent in Wistar rats. Journal of Medicinal Food. Vol. 11, № 1, 2008, pp. 127-132.

[22] Nematbakhsh, M., Zolfaghari, B., Eshraghi, F., Safari, T., Pezeshki, Z., and Sorooshzadeh, S. M. A. The effects of unripe grape extract on systemic blood pressure, nitric oxide production, and response to angiotensin II administration. Pharmacognosy research. Vol. 5, No 2, 2013, pp. 60.

[23] Quinones, M., Miguel, M., and Aleixandre, A. The polyphenols, naturally occurring compounds with beneficial effects on cardiovascular disease. Nutrición Hospitalaria. Vol. 27, $\mathrm{N}^{\mathrm{o}} 1,2011$, pp. 76-89.

[24] Deji, N., Kume, S., Araki, S. I., Soumura, M., Sugimoto, T., Isshiki, K.... and Uzu, T. Structural and functional changes in the kidneys of high-fat diet-induced obese mice. American Journal of Physiology-Renal Physiology. Vol. 296, № 1, 2009, pp. 118-126.

[25] Petrovski, G., Gurusamy, N., and Das, D. K. Resveratrol in cardiovascular health and disease. Annals of the New York Academy of Sciences. Vol. 1215, No 1, 2011, pp. 22-33.

[26] Rodrigues, A. D., Scheffel, T. B., Scola, G., dos Santos, M. T., Fank, B., de Freitas, S. C. V., .. and Salvador, M. Neuroprotective and anticonvulsant effects of organic and conventional purple grape juices on seizures in Wistar rats induced by pentylenetetrazole. Neurochemistry international. Vol. 60, No 8, 2012, pp. 799-805, 2012.

[27] Slater, S. J., Seiz, J. L., Cook, A. C., Stagliano, B. A., Buzas, C.J. Inhibition of protein kinase $\mathrm{C}$ by resveratrol. Biochim Biophys Acta. Vol. 1637, No 1, 2003, pp. 59-69.

[28] Matos, R. S., Baroncini, L. A. V., Précoma, L. B., Winter, G., Lambach, P. H., Kaiber, F., and Précoma, D. B. Resveratrol causes antiatherogenic effects in an animal model of atherosclerosis. Arquivos Brasileiros de Cardiologia. Vol. 98, $\mathrm{N}^{\mathrm{o}} 2,2012$, pp. $136-142$. 